\title{
NOTAS SOBRE EL CONTENIDO DEL PRINCIPIO DE LA DEMOCRACIA
}

\author{
NOTES ABOUT THE CONTENT OF DEMOCRATIC PRINCIPLE
}

Fecha de Recepción: 05/03/2011

Fecha de Aceptación: 20/03/2011

Pablo Marshall Barberán ${ }^{1}$

\begin{abstract}
Resumen:
El presente trabajo busca exponer aspectos sustantivos del principio de la democracia. Para ello se vale de las importantes investigaciones que, inspirado en la metodología de Carl Schmitt, E.W. Böckenförde ha realizado sobre el contenido y alcance de la cláusula democrática en el derecho constitucional positivo. Para ello se realiza una pequeña explicación del rol que cabe a la democracia en la teoría de las formas de gobierno para después tratar el fundamento, rol y aplicación que tiene el principio de la democracia como principio constitucional reconocido en el ordenamiento jurídico. Se finaliza con una breve aplicación de la teoría al caso del sistema jurídico chileno.
\end{abstract}

Palabras clave: Democracia, constitución, igualdad, libertad.

\begin{abstract}
:
This paper seeks to expose the substantive aspects of the principle of democracy. It focuses, in the important research, inspired by the methodology of Carl Schmitt, that EW Böckenförde been made about the content and scope of the democratic clause in positive constitutional law. To that objective, was make a brief explanation of the role that have democracy in the theory of forms of government. After that was explain the foundations, role and application of the principle of democracy as a constitutional principle recognized in legal system. It ends with a brief application of this theory to the case of the Chilean legal system.
\end{abstract}

Key words: Democracy, constitution, equality, freedom.

\footnotetext{
1 Abogado, Licenciado en Ciencias Jurídicas y Sociales, Escuela de Derecho, Universidad de Chile. Profesor de Derecho Constitucional en la Facultad de Derecho de la Universidad Austral de Chile. Correo: pmarshall@uach.cl
}

doi: 10.7770/RCHDYCP-V2N1-ART35 


\section{Introducción}

Carl Schmitt es una figura polémica. Ello se debe, además de su académicamente irrelevante adhesión al régimen nacionalsocialista, a que las ideas vertidas en sus obras son también polémicas. Sin embargo, no existe duda que Schmitt fue y continúa siendo una de las más influyentes figuras del derecho público. Uno de los pocos que en Alemania ha intentado rescatar sus ideas, y lo ha hecho de una manera notable, ha sido E.W. Böckenförde.

El estudio Ilamado "La democracia como principio constitucional", contenido en sus Estudios sobre el Estado de Derecho y la Democracia, es quizás el mejor artículo jurídico sobre la democracia jamás escrito y sin duda uno de los mejores textos sobre derecho constitucional que pueden encontrarse en idioma castellano. Este trabajo está no solo inspirado en dicho estudio, sino que pretende ser una revisión del mismo, un intento de introducir sus ideas a la comunidad jurídica nacional y finalmente evaluar la plausibilidad de aplicar las ideas en él contenidas al derecho constitucional chileno.

Teniendo lo anterior en consideración, pretende presentarse el principio de la democracia como principio constitucional. Para ello, la exploración debe comenzar con el lugar que cabe a la democracia como forma de gobierno, frente a sus alternativas. El fundamento de la democracia y su forma representativa constituye un antecedente ineludible para entender cuál es la forma en cómo opera la democracia como principio constitucional. Luego, se revisarán las maneras de legitimación democráti$\mathrm{ca}$, que pretenden implementar el principio democrático como un principio con fuerza normativa, para finalizar considerando cuál es la interpretación y la aplicación que puede tener la idea de legitimación democrática bajo la regulación de la Constitución Política de Chile.

\section{República, aristocracia y monarquía}

El principio de la democracia está presente en todas y cada una de las constituciones occidentales y se ha transformado, desde el imperio de la soberanía popular, en el principio que domina la organización y ejercicio del poder del Estado.

Si bien en la distinción fundamental de las formas de gobierno se diferencia claramente, en función de quién ejerce el gobierno del Estado, entre monarquía, aristocracia y democracia, el principio constitucional de la democracia ha coexistido con otros principios constitucionales que aparentemente aparecen como su negación, como el principio aristocrático y el monárquico.

Primero, se revisará una tipología de las clasificaciones relacionadas con el go- 
bierno, para a continuación revisar un concepto de monarquía y de aristocracia, que luego servirán para complementar una explicación de cómo los principios en que dichas formas de gobierno se fundan pueden existir en el Estado democrático.

\section{a) Clarificaciones en torno a las formas de gobierno}

Existen numerosas clasificaciones de los gobiernos, y la terminología empleada en cada una de ellas dista de ser unívoca. Pueden reconocerse al menos tres clasificaciones que tienen relevancia constitucional:

(1) la clasificación de Aristóteles, entre monarquía, aristocracia y democracia, en atención a quienes ejercen el poder del Estado y entre estas mismas respecto a sus versiones degeneradas. Nada mejor que leer al propio Aristóteles: "Ya que constitución y gobierno significan lo mismo y el órgano de gobierno es el poder soberano de la ciudad, es necesario que el poder soberano sea ejercido por una persona o unos pocos o la mayoría. Cuando el uno, pocos o la mayoría ejercen el poder en vista del interés general, entonces forzosamente esas constituciones serán rectas, mientras que serán desviaciones los que atienden al interés particular de uno, de pocos o de la mayoría [...]. Tenemos la costumbre de llamar monarquía al gobierno unipersonal que atiende al interés general, y aristocracia al gobierno de pocos [...] cuando se propone el bien común; cuando es el mayor número el que gobierna atendiendo al interés general recibe el nombre común a todas las constituciones politia [...] Las degeneraciones de las mencionadas formas de gobierno son: la tiranía de la monarquía, la oligarquía de la aristocracia, y la democracia de la politia. La tiranía, en efecto, es una monarquía orientada hacia el interés del monarca, la oligarquía hacia el interés de los ricos y la democracia hacia el interés de los pobres. Pero ninguna de ellas atiende al provecho de la comunidad (1279a-b)"2;

(2) la clasificación de Maquiavelo, entre monarquía y república, también atiende a cuántos ejercen el poder del Estado, si es solo uno o varios. La clave de la distinción, que asocia en la categoría república al gobierno de pocos y de muchos, es la de si existe necesidad de algún procedimiento para determinar la voluntad del gobierno o solo depende de la voluntad de la persona del monarca. En ese sentido en la república se requieren reglas para la toma de decisiones, las que no están presentes, según Maquiavelo, en la monarquía ${ }^{3}$ y

(3) la clasificación de Montesquieu, entre monarquía, república y despotismo, recogiendo la distinción de Maquiavelo, pero agregando la tercera categoría que es predicable de la forma de gobierno sin límites. En palabras del propio Montesquieu:

Aristóteles, La Política, citado en Bobbio, Norberto, La Teoría de las formas de gobierno en la historia del pensamiento político: año académico 1975-1976, Fondo de Cultura Económica, México, 2001, p. 34.

3 Bobbio, Norberto, obr. cit. p. 65. 
"Hay tres especies de gobiernos: el republicano, el monárquico y el despótico [...] Supongo tres definiciones, mejor dicho, tres hechos: uno, que el gobierno republicano es aquel en que todo el pueblo, o una parte de él, tiene el poder supremo; otro, que el gobierno monárquico es aquel en que uno solo gobierna, pero con sujeción a las leyes fijas y preestablecidas; y por último, que en el gobierno despótico el poder también está en uno solo, pero sin leyes ni frenos pues arrastra a todo y a todos tras su voluntad y caprichos" ${ }^{4}$.

Por otro lado, no debe confundirse la teoría de las formas de gobierno, con las formas de Estado (Estado unitario o federal) ni con los regímenes de gobierno (parlamentario o presidencial), no obstante existir numerosas conexiones entre ellas.

\section{b) Monarquía}

La monarquía, según Silva, es la "forma de gobierno en que el poder supremo corresponde con carácter vitalicio a un príncipe, designado generalmente según orden hereditario y a veces por elección" ${ }^{\prime \prime}$.

De este concepto pueden desprenderse las siguientes características, que pueden ser matizadas o criticadas: (a) La atribución al monarca del poder supremo. Esta atribución debe ser entendida como el poder del gobierno del Estado; (b) Vitalicio. El carácter vitalicio de la monarquía comprende la duración del gobierno del monarca por toda su vida. En esta característica está implícita la idea de que el monarca es irresponsable políticamente; y (c) Hereditario o electivo. La elección ha quedado limitada a casos marginales en las que el elemento hereditario está también presente.

La monarquía según Carl Schmitt puede tener diversas formas de justificación. Así, puede tener (1) una fundamentación religiosa que asimila al monarca con Dios o lo vincula de manera relevante; (2) una fundamentación que encuentre su fuente en la identidad entre el monarca y el padre de familia; (3) una fundamentación que se encuentra en el poder económico o patrimonial del monarca; o (4) puede basarse en el liderazgo de un caudillo que es requerido para satisfacer la necesidad de gobierno de una organización estatal ${ }^{6}$.

Sin embargo, el más importante caso de monarquía en la actualidad es el caso de las monarquías con base democrática, que descansan sobre la forma de legitimación de la soberanía popular y que tienen en el monarca nada más que un órgano constitucional que ejerce la jefatura del Estado.

\footnotetext{
Bobbio, Norberto, obr. cit. p. 126.

Silva, Alejandro, Tratado de Derecho Constitucional, Ed. Jurídica de Chile, Santiago, 1963, p. 238.

Schmitt, Carl, Teoría de la Constitución, Alianza, Madrid, 1983, pp. 275-276.
} 
Ello, evidentemente, no recibe su justificación en una de las formas teológica o patriarcal de justificación de la monarquía. Se puede justificar la existencia del monarca, como jefe de Estado, apelando a la teoría del poder neutro, que hizo famosa Schmitt. Cuando el jefe del Estado tiene garantizado su poder, la lucha política en la democracia no se llevará de manera tan extrema, en la medida que el más importante cargo dentro del Estado está ocupado de manera indefinida. La justificación reside en que el monarca está "por encima de los partidos" y se convierte en un poder neutral que tiene como finalidad ser el moderador de la vida política dentro del Estado y ser el representante de la unidad política del Estado ${ }^{7}$.

El principio democrático coexiste con la pervivencia de un monarca constitucional en numerosos países de Europa. Ello no implica actualmente que la democracia compita con la monarquía, como principio de legitimación del poder del Estado, sino que implica, más tímidamente, que el monarca conserva algunas atribuciones constitucionales. Esas atribuciones normalmente tienen un origen histórico y se expresan en la evolución institucional ininterrumpida de la monarquía constitucional hasta la democracia. Si bien el monarca en la democracia conserva un papel que puede ser presentado como meramente simbólico, y que se limita a dar cuenta de una tradición nacional o cultural que es asumida por la constitución. Pero también puede atribuírsele un rol institucional más relevante, que solo puede ser entendido cuando se entiende la distinción entre jefe del Estado, que puede ser ocupado por el monarca o por un funcionario electo, y jefe del gobierno, que en una democracia solo es admisible que sea ocupado por un funcionario electo.

Si se hace una abstracción, puede concluirse que la existencia en una república de un jefe de Estado como órgano unipersonal está inspirada en el principio monárquico.

\section{c) Aristocracia}

La aristocracia existe, señala Silva, "cuando el grupo de hombres que se han impuesto por los talentos, virtudes o servicios prestados a la colectividad [...] consolidan su prestigio y aseguran el uso y la continuidad del poder político mediante el privilegio de ser ellos mismos o sus descendientes llamados por derecho a ejercer las funciones públicas" ${ }^{8}$.

La aristocracia está ligada internamente con la idea de privilegio. La aristocracia como forma de gobierno atribuye alguna clase de privilegio en el acceso o el ejercicio del poder del Estado a los individuos que poseen una característica que los diferencia de los demás. La idea de este privilegio, como se verá más adelante, está

Schmitt, Carl, obr. cit. pp. 277-279.

8 Silva, Alejandro, obr. cit. p. 241. 
en una posición contradictoria con la idea de igualdad política, que es una base fundamental y un principio complementario de la democracia como forma de gobierno. La igualdad política implica que no existen privilegios. Allí donde las instituciones estatales consagran alguna clase de privilegios políticos, existe una erosión de la democracia, que debe estar justificada debidamente.

La recepción del principio aristocrático en el Estado democrático se ha realizado principalmente a través de la adopción del bicameralismo: una estructuración del parlamento en dos cámaras. La idea del bicameralismo, al menos en su origen, se fundó en la idea de dividir al órgano legislativo en dos, para controlar el poder de la democracia. La cámara baja estaría compuesta por representantes del pueblo, la cámara alta estaría compuesta por representantes, que con exclusividad, pertenecieran a las clases más acomodadas. Ello encuentra una abierta tensión entre el bicameralismo, fundado en la aristocracia, y el principio democrático. El respeto irrestricto de la democracia exige la representación del pueblo y nadie más que el pueblo. Siendo el unicameralismo el sistema de organización del órgano legislativo que se concilia mejor con la democracia.

Esa tensión ha tendido a eliminarse, sin embargo, mediante la adopción de un parlamento unicameral, o de la eliminación de la representación aristocrática de la segunda cámara. Con todo, esta última alternativa no está desprovista de un contenido limitativo de la democracia. Por tres razones: primero, porque la democracia consiste en el gobierno del pueblo como unidad política, y la existencia de dos representaciones, cualquiera sea su clase, erosiona la representación de esa unidad; segundo, porque el bicameralismo ha conservado vigencia, más allá del principio aristocrático, como una forma de organización propia del Estado de derecho que pretende, deliberadamente, imponer límites a la democracia; y tercero, porque en la estructura de los sistemas bicamerales, cuando no se fundan en una representación especial, tienden a conservar cierta identidad aristocrática. Ejemplo de ello es la mayor edad que se exige para acceder al Senado (art. 48 vis-à-vis art. $50 \mathrm{CPol}$ ) o el menor número de integrantes de este (art. 47 vis-à-vis art. $49 \mathrm{CPol}$ ).

\section{d) Democracia y república}

La república es algo distinto a la democracia, como ya se ha visto en las reflexiones preliminares. La relación de la república con la democracia dependerá del concepto de república que se presente.

Un concepto formal de república se define por la relación de negación que tiene con el concepto de monarquía ${ }^{9}$. El concepto formal de república dice relación con una jefatura del Estado no monárquica. De una manera más general, puede decirse que en

$9 \quad$ Schmitt, Carl, obr. cit. p. 221. 
la república, de manera opuesta a la monarquía, las autoridades políticas deben cumplir con dos principios: (1) principio de la temporalidad, que exige que las autoridades solo desempeñen sus funciones durante un periodo de tiempo limitado; y (2) el principio de electividad, que exige que las autoridades sean elegidas y que su investidura no dependa de un régimen hereditario del titular del cargo, sino de una elección ${ }^{10}$.

Algunos postulan que además debe atenderse al principio de responsabilidad, que es aquel que exige que los titulares de los órganos del Estado respondan ante el pueblo por su actuaciones ${ }^{11}$. Sin embargo, el principio de responsabilidad está implícito, al menos en lo que respecta al jefe de Estado, en su elección por parte del pueblo durante un periodo de tiempo determinado ${ }^{12}$.

En una república democrática el órgano que ejerce la jefatura del Estado es sometido a las reglas de elección democráticas. Sin embargo, el principio de la democracia no se ve afectado de manera relevante por la existencia de un "vértice monárquico" dentro de un sistema que admite e implementa el principio de la democracia de manera relevante, por ejemplo, en un Estado democrático con un jefe de Estado hereditario ${ }^{13}$.

El concepto material de república exige una clara dirección del Estado respecto a perseguir objetivos comunes y a pensar en lo que es mejor para la comunidad política. El republicanismo, en este sentido, se presenta como una alternativa al liberalismo, al plantear una justificación diversa del Estado, ya no en la persecución de las condiciones que posibiliten la búsqueda y consecución del plan de vida individual, sino en la búsqueda y realización del plan de vida en común, presentando especiales objeciones a la incorporación de intereses individuales en el discurso público y especialmente en la influencia o dominación del Estado por parte de un grupo o individuo ${ }^{14}$.

10 Roldán lo describe de la siguiente manera: "La división de los gobiernos en monárquicos y republicanos se ha fundado en la naturaleza del título de donde deriva su autoridad el jefe del estado. / En la monarquía este título es hereditario, mientras que en las repúblicas procede de la elección. Otra diferencia, no menos importante, consiste en que el monarca gobierna por toda la vida, al paso que el funcionario que desempeña la primera magistratura en las repúblicas, no permanece en el poder sino por un tiempo limitado". (Roldán, Alcibíades, Elementos de Derecho Constitucional de Chile, Imprenta Lagunas \& Co., Santiago, 1924, p. 51.). También véase Lastarria, José Victorino, Elementos de Derecho Público 1865, p. 50.

11 Vivanco, Ángela, Curso de Derecho Constitucional, Ed. Universidad Católica de Chile, Santiago, 2004, p. 84.

12 Ello, a menos que se esté dispuesto a justificar que la irresponsabilidad del jefe de Estado es una nota esencial de la forma de gobierno monárquica.

13 Böckenförde, Ernst Wolfgang, La democracia como principio constitucional, Ed. Trotta, Madrid, 2002, p. 127.

14 Sobre el republicanismo, véase Ovejero Lucas, Félix; Martí Màrmol, José Luis; Gargarella, Roberto, Nuevas ideas republicanas: autogobierno y libertad, Paidós Ibérica, Barcelona [etc.], 2004; Pettit, Philip, Republicanismo, una teoría sobre la libertad y el gobierno, Paidós, Barcelona, 1999. 
La relación de la democracia con el republicanismo estará condicionada a las ideas imperantes dentro de la comunidad política de que se trate. Es en ese sentido, contingente. Es tan posible hablar de una democracia liberal como de una democracia republicana.

Un concepto material de república, sin embargo, plantea muchos más problemas de determinación y no se plantea como un concepto propio de la dogmática constitucional, sino que de la teoría de la justicia política. Es en ese sentido que la alusión a la forma republicana que la Constitución Política realiza al señalar que "Chile es una república democrática" (art. $4^{\circ} \mathrm{CPol}$ ) tiende a asociarse con un concepto formal de república ${ }^{15}$.

\section{Fundamentos de la democracia}

La democracia como principio constitucional de organización y ejercicio del poder del Estado se afirma en dos ideas fundamentales: la libertad política y la igualdad política.

La democracia es en sí misma la afirmación del ejercicio libre del gobierno por parte del pueblo, no sujeto a límites o restricciones. En ese sentido, la integración de otros bienes o fines ajenos a la libertad del pueblo de autogobernarse, no parecen ser aceptados por el principio de la democracia. Así, la protección de los derechos fundamentales en general, no forma parte de la democracia. Tampoco forma parte de la democracia, la consecución de bienestar y crecimiento económico. No puede, de esta manera, afirmarse que la democracia es un medio o instrumento para lograr un fin que sea distinto a la realización misma de la democracia como libertad e igualdad del pueblo ${ }^{16}$.

\section{a) La libertad política}

La libertad política puede ser objeto de confusión. La libertad política hace referencia a la ausencia de restricciones para la formación de la voluntad del pueblo. Pero la autonomía de voluntad del pueblo parte de la base, de la autonomía de la voluntad de los ciudadanos. En este sentido, la democracia aparece como un modelo que equilibra la calidad de ciudadano como destinatario del poder del Estado, pero que, al mismo tiempo, encuentra en la voluntad de los mismos que se encuentran sometidos él, su fundamento y ejercicio ${ }^{17}$.

15 Schmitt, Carl, obr. cit. p. 221.

16 Cft. Barros, Enrique, La democracia como forma del poder: un enfoque normativo /en/ Estudios Públicos, $N^{\circ} 26,1987$.

17 Böckenförde, Ersnt, obr. cit. p. 77. 


\section{(i) Los derechos fundamentales democráticos}

El tránsito de la autonomía del individuo a la autonomía de la comunidad política es un proceso que está mediado por la garantía fundamental de la libre participación individual en el proceso de decisión colectiva. Esa mediación está institucionalizada en los derechos fundamentales democráticos como "aseguramiento de las condiciones procedimentales de formación de la voluntad política" ${ }^{18}$. Primariamente, el voto y el acceso a los cargos públicos (art. $13 \mathrm{CPol}$ ), como medios directos de producción de la voluntad colectiva. Secundariamente, la libertad de expresión, información y prensa (art. $19 \mathrm{~N}^{\circ} 12 \mathrm{CPol}$ ), la libertad de reunión (art. $19 \mathrm{~N}^{\circ} 13 \mathrm{CPol}$ ) y la libertad de asociación (art. $19 \mathrm{~N}^{\circ} 15 \mathrm{CPol}$ ), que constituyen fórmulas que garantizan la posibilidad de que dichos medios primarios efectivamente canalicen la voluntad individual a la voluntad colectiva, mediante la formación de opinión pública libre como base de la decisión política ${ }^{19}$.

\section{(ii) La libertad política y la democracia como principio formal}

La libertad política tiene, como autonomía colectiva ya configurada, la "facultad de disposición sobre el orden político y jurídico". En ese sentido, no está vinculada por contenido alguno y solo dice relación con la contingencia que tales contenidos presentan a la luz de la posibilidad de renovarlos, eliminarlos o mantenerlos. La libertad política como autonomía colectiva es vacía de contenido y, por tanto, solo una libertad formal, abierta a las posibilidades y contingencias.

La democracia como concreción permanente de la libertad política, asegura la revisabilidad de las decisiones políticas anteriores, y en ese sentido, debe conformase un estado de cosas que ponga límite a las interferencias externas al proceso de formación de voluntad. Esas interferencias vienen dadas fundamentalmente por la intervención de poderes de facto que actúan en representación de concepciones o intereses particulares, y que puede llegar a generar la exclusión de la participación de un grupo determinado o de la comunidad entera, por ejemplo, las interferencias provenientes de los medios de comunicación o de los partidos políticos ${ }^{20}$.

La libertad política como fundamento de la democracia no exige la garantía de otros derechos fundamentales que no sean los aquí denominados democráticos. Esa exigencia está planteada por el principio del Estado de derecho, que en ese sentido limita y colisiona con la democracia ${ }^{21}$. Lo mismo sucede con los arreglos institucio-

18 Böckenförde, Ernst, obr. cit. p. 81.

19 Böckenförde, Ersnt, obr. cit. p.78.

20 Böckenförde, Ersnt, obr. cit. p.82.

21 Böckenförde, Ersnt, obr. cit. p.80. La noción formal de la democracia, que hasta aquí se ha planteado se enfrenta a una noción sustancial de democracia, también denominada democracia constitucional.

Revista Chilena de Derecho y Ciencia Política - Vol. 3, № 1, Año 2, 2011 
nales que se justifican en la protección de determinados objetos o bienes constitucionales, como por ejemplo, el sistema de quórum diferenciado o dificultado para la dictación de leyes consideradas importantes (art. $66 \mathrm{CPol}$ ) o de la distinta dificultad de reforma para distintos capítulos de la Constitución Política (art. 127 CPol). El objetivo de dichos arreglos institucionales puede describirse de la siguiente forma: "Impedir una 'revolución legal', esto es, una transformación que destruya por medios legales los fundamentos del orden político y jurídico, y por eso pretenden vincular jurídicamente también a generaciones futuras. Son en realidad un signo de que la comunidad política $[. .$.$] ha perdido la confianza en sí misma"22.$

Puede asociarse esta clase de trabas con la limitación de la expresión del pueblo. Ello puede repercutir, de forma traumática, en el desborde de la expresión del pueblo respecto de los cauces institucionalmente establecidos. En la medida que una organización democrática considere adecuadamente la libertad del pueblo de decidir su destino, la expresión de la soberanía del pueblo, como expresión del poder político de aquel, expresada a través de las formas que no se adecuan a la constitución vigente, tenderá a ser canalizada o refrenada ${ }^{23}$.

\section{(iii) Pluralismo político y sus límites}

El pluralismo político puede ser entendido como una consecuencia necesaria de la libertad política en una democracia. El pluralismo político exige que los más diversos puntos de vista puedan ser expresados y sostenidos en el discurso público. En este sentido, el pluralismo político está estrechamente relacionado con los derechos fundamentales democráticos, en especial la libertad de expresión y de asociación. En relación con esta última, particular interés tiene comprender cómo el principio del pluralismo político afecta la existencia y actuación de los partidos políticos.

Esta noción sustancial se configura por la combinación de la democracia con otros elementos, típicamente pertenecientes a la doctrina del Estado de derecho. Por ejemplo, se señalan como elementos integrantes de la democracia, en este sentido sustancial, a los derechos fundamentales y a la separación de funciones entre los órganos del Estado.

La configuración del Estado moderno como Estado de derecho democrático o como Estado democrático constitucional, considera la combinación de los principios de la democracia y del estado de derecho. Sin embargo, considerar que los elementos integrantes del Estado de derecho forman parte de la democracia puede conllevar a equívocos.

El más importante de todos es aquella carga de argumentación que se establece a favor de una decisión democrática. Las limitaciones que pretendan implementarse frente a una decisión de ese tipo, tienen necesariamente que estar fundadas, ya en la propia protección de la democracia o en la protección del principio de Estado de derecho. Este principio, como un principio que pretende limitar el poder del Estado frente a la esfera individual, consiste en un recurso lícito en una argumentación que pretenda poner límites a la democracia.

22 Böckenförde, Ersnt, obr. cit.

23 Véase Marshall, Pablo, La soberanía popular como fundamento del orden estatal y como principio constitucional /en/ Revista de Derecho de la Pontificia Universidad Católica de Valparaíso, № 35, 2010. 
El principio del pluralismo político considera que todos los partidos, grupos y tendencias políticas pueden buscar hacerse del gobierno. El Estado debe abstenerse de interferir y debe favorecer la mayor y más diversa expresión y representación política, así como la libre constitución y desarrollo de grupos y partidos políticos.

El pluralismo está exigido por la libertad y igualdad la política. Por la libertad, en la medida que la expresión de todas las alternativas es necesaria para la libre determinación del pueblo en la búsqueda de la mejor de ellas, así como por la necesidad de la formación de la voluntad colectiva, medida por el establecimiento de derechos fundamentales democráticos. Es exigida por la igualdad política porque considerar alguna alternativa como inviable sería no tener en cuenta como iguales a aquellos que la sostienen.

El principio del pluralismo se puede encontrar limitado. Tal limitación puede dar paso a diferentes modelos de pluralismo limitado, en los cuales se pone coto a la libre asociación y expresión de alternativas políticas que atenten contra o intenten eliminar a la democracia misma. Así, pueden encontrarse modelos de limitaciones fundadas en la expresión de violencia política por parte de grupos organizados, típicamente en la forma de proscripción del terrorismo (art. $9^{\circ} \mathrm{CPol}$ ). Luego, pueden encontrarse modelos de limitaciones directamente dirigidos a censurar y proscribir las ideas o opiniones políticas que se presenten contrarias a la democracia (art. $19 \mathrm{n}^{\circ} 15$ inc. $\left.6^{\circ}\right)^{24}$.

La limitación del pluralismo estará justificada cuando se presente como la garantía de la democracia frente a un peligro grave o a su destrucción. No se encontrará justificada, allí donde los límites constituyan solamente barreras legales para la participación de grupos políticos disidentes, como fue el caso del texto original de la Constitución Política ${ }^{25}$. Dicho artículo fue reemplazado por el actual 19 NN $^{\circ} 15$ inc. $6^{\circ}$, que establece: "La Constitución Política garantiza el pluralismo político. Son inconstitucionales los partidos, movimientos u otras formas de organización cuyos objetivos, actos o conductas no respeten los principios básicos del régimen democrático y constitucional, procuren el establecimiento de un sistema totalitario, como asimismo aquellos que hagan uso de la violencia, la propugnen o inciten a ella como método de acción política. Corresponderá al Tribunal Constitucional declarar esta inconstitucionalidad".

${ }_{24}$ Molina, Hernán, Instituciones Políticas, LexisNexis, Santiago, 2006, pp. 176-182.

$25 \mathrm{El}$ antiguo artículo $8^{\circ}$ establecía: "Todo acto de persona o grupo destinado a propagar doctrinas que atenten contra la familia, propugnen la violencia o una concepción de la sociedad, del Estado o del orden jurídico, de carácter totalitario o fundada en la lucha de clases, es ilícito y contrario al ordenamiento institucional de la República (inc. $1^{\circ}$ ). / Las organizaciones y los movimientos o partidos políticos que por sus fines o por la actividad de sus adherentes tiendan a esos objetivos, son inconstitucionales (inc. $\left.2^{\circ}\right)^{\prime \prime}$. 
Respecto a este artículo, es difícil sostener que la proscripción, solo de posiciones políticas y no de actos pueda ser amparada por el pluralismo político. En ese sentido, existe una tensión evidente entre el encabezado y el resto del inciso.

\section{B) La igualdad política}

Al igual que con la libertad política, la igualdad política está íntimamente ligada a la democracia. La igualdad política se implica en el concepto de democracia en la medida que exige que no sean solo algunos quienes sean considerados como punto de partida para la formación de la voluntad general, sino que sean todos. La libertad política debe ser asegurada a todos los integrantes del pueblo y debe serlo de igual manera ${ }^{26}$.

La igualdad política específicamente exige la garantía de la igualdad de oportunidades para acceder al poder político y de manera concreta, de iguales derechos de participación. Solo la igualdad de derechos de participación puede garantizar la igualdad de oportunidades de influencia en el proceso de formación de la voluntad política del pueblo ${ }^{27}$.

La igualdad política, al igual que la libertad política, se restringe al ámbito de la "participación en la formación de la voluntad política" y no exige la igualdad ni la libertad de otros ámbitos de la vida social ${ }^{28}$. Sin embargo, bien entendida, la igualdad política parece descartar todos los obstáculos para la realización de la igualdad en otros ámbitos de la vida social. La búsqueda de la igualdad social puede convertirse en el contenido de la política democrática, que como se señaló es, en un principio, vacía de contenido ${ }^{29}$.

El criterio para la aplicación de la igualdad política es la calidad de ciudadano. Esto es, la pertenencia a la comunidad política o pueblo. Se imputa a la igualdad política, en este sentido, dos caracteres: uno estrictamente formal y otro de carácter material.

\section{(i) Igualdad política formal y sustancial}

La igualdad política formal consiste en la asignación de los mismos derechos políticos a cada ciudadano. En ese sentido, la asignación de un voto a cada ciudadano, suprimiendo además cualquier diferencia de ponderación o valor posible, viene exigida por razones de igualdad política. Cualquier privilegio es contrario a

6 Böckenförde, Ersnt, obr. cit. p. 82; Schmitt, Carl, obr. cit. p. 224.

27 Böckenförde, Ersnt, obr. cit. p. 83.

28 Cft. Schmitt, Carl, obr. cit. p. 223.

29 Böckenförde, Ersnt, obr. cit. p. 83. 
la igualdad democrática y por tanto solo es admisible por razones de peso. En este sentido no solo el derecho a sufragio debe estar determinado por la igualdad política, sino la configuración del sistema electoral: cada voto debe valer igual (art. $15 \mathrm{CPol}$ ), tanto aritméticamente como efectivamente ${ }^{30}$. Lo mismo es predicable del sistema de partidos políticos, en el que se debe garantizar la igual libertad de participación y la igualdad de oportunidades de estos, en cuanto mediadores de la voluntad de los ciudadanos en el Estado y de los representantes del pueblo ante el parlamento ${ }^{31}$.

Por otro lado, se habla de la faz sustancial de la igualdad política cuando esta se predica solo de los ciudadanos y entre los ciudadanos. Las demás personas carecen de la particular condición que los hace merecedores de la libertad política: "Los ciudadanos saben 'iguales' y de acuerdo sobre cuestiones de principio del orden político; consideran la experiencia y la vivencia de sus conciudadanos como algo no existencialmente distinto o extraño, y están dispuestos sobre esta base a compromisos y a una aceptación leal de la decisiones de la mayoría"32.

Esta es la dimensión en la que la igualdad política y la igualdad general se muestran claramente diversas. La igualdad política exige la asignación de iguales derechos políticos. La igualdad general solo exige la asignación de los derechos que son reconocidos por la comunidad a todas las personas, independiente de su calidad de ciudadano. En esta posición se encuentran los extranjeros y los no ciudadanos. El futuro de la relación del extranjero con la comunidad política marcará también el futuro de la igualdad que le será asignada a su estatus ${ }^{33}$.

\section{(ii) Identidad y liderazgo: la solución de la tensión entre identidad y representación}

Si se comprende que el principio de la identidad exige que en la democracia sea el pueblo quien ejerce el poder del Estado sobre sí mismo, se necesita una explicación para la conciliación entre la igualdad y la identidad con la forma representativa de democracia.

De la igualdad política se sigue que no hay diferencias entre gobernantes y gobernados. Lo que normalmente se presenta como una diferencia es en realidad una situación, el gobernante ocupa un cargo o función dentro del Estado, el gobernado no. Eso no es suficiente para afirmar que no hay una identidad entre los gobernantes y los gobernados; ambos son igualmente ciudadanos y no son más que eso. La naturaleza transitoria del ejercicio de cargos públicos y la responsabilidad que puede perseguir-

\footnotetext{
Böckenförde, Ersnt, obr. cit. pp. 84-85. En este sentido las barreras electorales afectan el principio de igualdad política.

31 Böckenförde, Ernst, obr. cit. pp. 85-86.

32 Böckenförde, Ernst, obr. cit. p. 88.

33 Böckenförde, Ernst, obr. cit. pp. 86-88; Schmitt, Carl, obr. cit. pp. 224-230.
} 
se por el pueblo garantizan la igualdad y la identidad, no permitiendo el ejercicio del dominio político por parte de personas o grupos más que de forma transitoria ${ }^{34}$.

La característica igualdad e identidad entre gobernantes y gobernados, necesariamente acarrea el principio del liderazgo como principio de la atribución del gobierno en la democracia. Este se basa en el reconocimiento libre de los seguidores de un partido o candidato y, además, está sometido a la competencia por el liderazgo que, por cierto y dada la ausencia de un dominio asegurado institucionalmente, se mantiene como una competencia continuada35. En términos de Schmitt: "La inevitable diferencia práctica entre gobernantes y gobernados no puede pasar a ser una distinción y singularización cualitativas de las personas gobernantes. Quien gobierna en una Democracia no lo hace porque posea las condiciones de una capa superior cualitativamente mejor [...] gobierna solo porque tiene la confianza del pueblo. No tienen ninguna autoridad nacida de una naturaleza especial [...]. Aquellos que gobiernan se diferencian a través del pueblo, pero no frente al pueblo [... $]^{\prime 36}$.

\section{La democracia como democracia representativa}

Existen dos concepciones de democracia, que pretenden encarnar la idea expresada en el concepto de democracia como gobierno del pueblo. Ellas son la democracia directa y la democracia representativa.

La democracia directa puede ser presentada como la aplicación plena o estricta del principio de identidad entre gobernantes y gobernados ${ }^{37}$. Los destinatarios del poder del Estado deben ser los mismos (allí la identidad) que quienes ejercen el poder de decidir. Entre gobernantes y gobernados no hay nadie que pueda reclamar un autoridad propia frente al pueblo ${ }^{38}$.

Por otro lado, la democracia representativa consiste en la forma de gobierno cuya legitimidad se basa en la autorización que el pueblo realiza para que el poder del Estado sea ejercido por órganos que actúan por sí mismos.

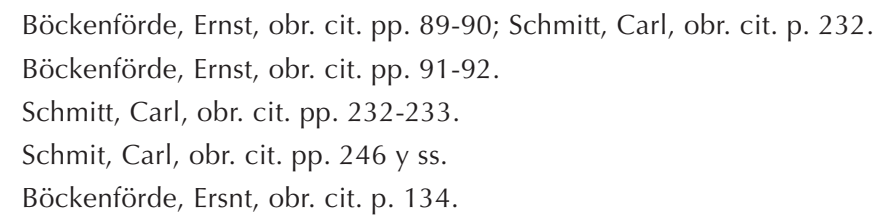




\section{a) La democracia directa}

La forma de la democracia directa reclama para sí, y esa idea es muy difundida, el título de ser la forma auténtica de democracia. Ello puede fundarse en al menos dos ideas: (i) el primer antecedente histórico en la democracia ateniense, en que las decisiones más relevantes eran tomadas por una asamblea en la que participaba todo el pueblo; y (ii) la idea de Rousseau de que la soberanía que reside esencialmente en el pueblo no es susceptible de ser representada.

Desde esta perspectiva, la introducción de agentes estatales representativos que asumen la dirección del Estado, incluso cuando reciben legitimación del pueblo y actúan a nombre de él, debe entenderse como un déficit democrático que solo es justificado por razones pragmáticas vinculadas a las circunstancias del Estado moderno, esto es, (i) la extensión de su territorio y (ii) su inmensa población ${ }^{39}$. Esta tesis se vuelve relevante para la interpretación de la relación que hay entre las instituciones de democracia directa existentes en la democracia representativa, que en la medida que se perciben como un plus de democracia, deben ser preferidas frente a las instituciones representativas, cuando las razones pragmáticas lo permitan ${ }^{40}$. Según esta concepción, la democracia representativa aparece como una forma inferior de democracia.

Böckenförde considera que esta tesis está expuesta a una crítica incontestable. Considera que la democracia directa no solo debe rechazarse por razones pragmáticas, sino porque tampoco es realizable, y en ese sentido ideal, desde un punto de vista teórico. Funda su crítica en tres ideas principales.

La primera, afirma que para entender cómo la voluntad del pueblo puede ser entendida como la voluntad de una unidad, esa voluntad solo puede ser manifestada como una respuesta a un estímulo. En la medida que el pueblo es una realidad sin forma y para su actuación directa requiere actualizarse en una forma. Esa forma está directamente determinada por el estímulo. Por ejemplo, la decisión del pueblo en una consulta popular estará determinada por cuál será la pregunta que el pueblo responderá. La cuestión de quién hace dicha pregunta no es, entonces, irrelevante.

\footnotetext{
39 Molina expone que existe otro tipo de consideraciones pragmáticas, que se encuentra en que "los gobiernos deben abordar problemas de enorme complejidad, que requiere de conocimiento especializados y, al mismo tiempo, amplios y generales./Por consiguiente, esta formación científica, técnica y política no la tiene la generalidad de las personas. De ahí la necesidad que los gobernantes sean una selección de personas que, por su formación y competencia, aseguren la mayores probabilidades de acierto en el gobierno" (Molina, Hernán, obr. cit. p. 165). Esta clase de argumento es inadmisible porque entiende que la tarea de gobernar es una tarea que solo puede ser abordada por una clase ilustrada de personas, lo que se funda, en última instancia, en la posibilidad de distinción y privilegio, idea excluida por el principio de igualdad política. La necesidad de mayor información de todo tipo es una necesidad del gobierno, pero eso habla que los representantes del pueblo no puedan recurrir para ese efecto a los analistas que estimen convenientes.

40 Böckenförde, Ernst, obr. cit. p. 135.
} 
Siempre se requerirá, como en la democracia ateniense, alguien que haga la pregunta que el pueblo responde en la democracia directa. La cuestión de si ese sujeto puede ser cualquiera o debe ser alguien legitimado por la elección de la mayoría, constituye una primera razón, salvo que la respuesta no sea obvia, para afirmar que la representación democrática es ineludible ${ }^{41}$.

El segundo argumento es complementario del anterior. Los individuos que componen el pueblo tiene intereses plurales y su principal interés no está en la participación política. Luego, existe una tendencia a que grupos de interés, que están asociados en torno alguna clase de interés particular, intervengan en el espacio público de una manera activa. Entender la democracia directa como forma primaria de democracia, es conceder que los grupos de poder, guiados por la defensa de sus propios intereses, tienen un espacio suficiente para superponer esos intereses particulares al interés general: "El manto de la democracia directa vela la estructura oculta de la representación que se desarrolla en esta situación", representación ya no del pueblo, sino de sectores del pueblo ${ }^{42}$.

La tercera y última idea que Böckenförde sostiene es la afirmación de que cualquier clase de organización colectiva, si quiere comprenderse como tal, necesita un aparato organizado de dirección. Para entender al pueblo como un ente colectivo que pueda afirmar su unidad, se requiere conferirle una organización que dirija su acción y permita unificar su voluntad: "Por su propia naturaleza, en ellas [las unidades políticas] se da de un modo continuo y con carácter necesario una relación entre pregunta y respuesta, entre la acción de unos pocos y la aprobación o reprobación de muchos" $^{\prime 4}$.

\section{b) La democracia representativa}

El principio de democracia establecido en las constituciones modernas está referido fundamentalmente a un modelo representativo. En este sentido, la referencia a la democracia no es a la democracia directa. La existencia de órganos representativos de dirección de la acción del Estado, que puedan actuar por sí mismos, es, por tanto, una necesidad de la forma de Estado democrática. Vista de esta forma, la democracia no es la cancelación del poder de los órganos del Estado, para darle ese poder al pueblo, sino que es "admitir la existencia de ese poder de dirección y de esos representantes, en conferirles estabilidad en lo posible, pero al mismo tiempo, en someterlos a legitimación democrática [...] para que su acción pueda valer como una acción autorizada por el pueblo y en nombre del pueblo $[\ldots]^{\prime \prime 4}$.

1 Böckenförde, Ernst, obr. cit. pp. 136-137; Schmitt, Carl, obr. cit. pp. 269-271.

42 Böckenförde, Ernst, obr. cit. pp. 138-139.

43 Böckenförde, Ernst, obr. cit. p.141.

44 Böckenförde, Ernst, obr. cit. pp.142-143. 
Böckenförde presenta tres elementos específicos para la organización de una democracia representativa: (a) "tiene que ser posible una permanente remisión el pueblo del poder de decisión y de dirección de los órganos representativos que actúan por sí"; (b) el poder de dirección de los representantes debe estar establecido como una competencia estatal limitada jurídicamente; y (c) dicho poder de decisión y dirección debe poder ser corregido o contrapesado directamente por el pueblo, ya sea retirando los representantes, ya sea mediante decisión directa sobre ciertos asuntos. Los instrumentos de democracia directa, en este modelo, se incorporan de manera excepcional como factores de equilibrio que corrigen y contrapesan ${ }^{45}$.

\section{c) Sobre la representación}

La representación se implementa a través de la acción de los órganos representativos. Dicha acción no debe estar orientada por los intereses particulares de los titulares de los órganos, sino que debe estar orientada por la voluntad pública destinada a satisfacer las demandas del pueblo en su conjunto ${ }^{46}$. Así, la acción representativa de los órganos del Estado debe ser determinada por la voluntad general, que no es una suma de los intereses particulares. Por ejemplo, la actividad del Presidente de la República debe estar orientada por la voluntad popular, que es encarnada, en la democracia representativa, en el concepto de opinión pública.

¿Cómo puede determinarse cuál es la voluntad del pueblo? Esa pregunta plantea la paradoja de necesariamente recurrir a la manifestación de los procesos de formación de la voluntad colectiva, pero sin incurrir en el error de entender que la voluntad general es la suma de la voluntad empírica de todos los ciudadanos integrantes del pueblo. La respuesta de Böckenförde, parece pasar por entender que es necesario un momento normativo, en la determinación de la voluntad general, que pasa no por actuar a nombre del pueblo, sino en interés del pueblo. En la medida que dicho interés no puede encontrar su base sino en la manifestación del pueblo de sus necesidades e intereses particulares, la crítica paternalista no puede ser ocupada contra esta idea ${ }^{47}$. La representación significa, entonces, "la actualización y la manifestación de la identidad misma del pueblo, sita en los ciudadanos, y significa asimismo la actuación y la manifestación de una cierta idea, viva en la conciencia de los ciudadanos, sobre cómo deben tratarse las cuestiones generales y cómo debe llevarse a cabo la mediación entre las necesidades e intereses [particulares] y lo general"48.

45 Böckenförde, Ernst, obr. cit. pp. 143-144. La forma de la democracia representativa con instrumentos de democracia directa como formas de contrapeso y corrección, es a veces vista como una tercera forma de democracia diversa, denominada democracia semidirecta. Por ejemplo, Molina, Hernán, obr. cit. pp. 167-174.

46 Böckenförde, Ernst, obr. cit. pp. 147-148.

47 Pitkin, Hanna, El concepto de representación, Centro de Estudios Constitucionales, Madrid, 1985, p. 234.

48 Böckenförde, Ernst, obr. cit. p. 151. 
El órgano representativo por excelencia es el parlamento. Sin embargo, en los sistemas de gobierno presidenciales, el Presidente de la República es también un representante del pueblo.

Todos los órganos representativos son representantes del pueblo y, en ese sentido, no representan a nadie más que al pueblo como unidad política ${ }^{49}$. Pese a que los representantes sean elegidos por una fracción de los ciudadanos electores, dependiendo del sistema de circunscripciones electorales que se establezca, estos no representan a los electores que sufragaron por ellos, ni siquiera a todos los ciudadanos de dicha fracción, sino que representan al pueblo en su totalidad. Esto es evidente en el caso del Presidente de la República, elegido por todos los ciudadanos. Pero no es en absoluto evidente en el caso de los parlamentarios. Existen dos posturas contrapuestas respecto a la relación de los parlamentarios con sus electores (allí donde el pueblo se encuentra fraccionado para elegir sus representantes $)^{50}$.

La primera, argumenta que quien es representante del pueblo en su unidad política es el órgano representativo, en este caso, el parlamento. Dicha situación es perfectamente compatible con la existencia de relaciones particulares de representación entre la fracción del pueblo y el representante miembro del parlamento. La conformación de este como órgano representativo, se lleva a cabo sumando las relaciones de representación individuales entre representantes y ciudadanos: "una de las características más importantes del gobierno representativo es su capacidad para resolver las conflictivas pretensiones de las partes sobre la base de su común interés en el bienestar del todo" ${ }^{\prime \prime 1}$.

Esta postura puede encontrar apoyo en la existencia de circunscripciones territoriales más bien pequeñas para la elección de representantes y en tendencia a la personalización de las candidaturas y al voto personalizado ${ }^{52}$.

La segunda, argumenta que tanto el parlamento en su totalidad como cada uno de los representantes que lo componen, tiene la calidad de representante del pueblo en su totalidad, y en ese sentido, su vinculación con los ciudadanos que lo eligieron es contingente y limitada. Esta postura encuentra su apoyo en el concepto de pueblo como unidad política que es no susceptible de ser representado por parcialidades en la configuración del parlamento y en la contingencia de los sistemas de elección de parlamentarios con base en circunscripciones pequeñas y a la personalización del voto. También puede encontrar apoyo en la idea de que existe un interés del pueblo

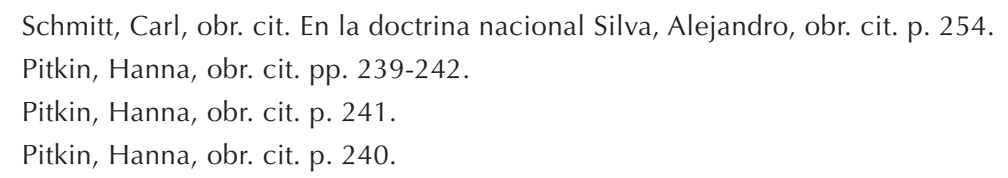


en los intereses de los distintos sectores integrantes del mismo ${ }^{53}$. Tal cómo existe ese sistema, podría existir un sistema de grandes circunscripciones territoriales con un número elevado de representantes a elegir en cuyo caso la relación personal entre representante y los ciudadanos electores tendería a difuminarse.

\section{La democracia como forma de gobierno y como principio constitucional}

La democracia, en términos de Schmitt, es la forma política del principio de identidad. La democracia, entonces, exige que sea el pueblo el que gobierne. El pueblo, debe coincidir, para que el principio de la identidad sea implementado, con la categoría individual de destinatario del poder del Estado. Así, el gobernante será idéntico al gobernado ${ }^{54}$.

La integración del concepto de pueblo depende de una concepción de ciudadano como categoría de pertenencia individual a la comunidad política. En este sentido, la democracia como gobierno del pueblo, presupone una extensión de la ciudadanía tan lejos como sea posible, conservando la idea de identidad entre gobernantes y gobernados.

\section{a) La relación de la democracia con el principio de soberanía popular}

La democracia puede entenderse, como ya se señaló, como una concreción o realización del principio de la soberanía popular. La democracia es el principio que determina quién tiene el ejercicio del poder del Estado que, mediante el principio de soberanía popular, recibe su fundamento en el pueblo. Lo que la democracia sostiene es que el poder del Estado que proviene del pueblo, debe ser ejercido también por el pueblo $^{55}$.

El pueblo en ejercicio del poder constituyente, decide conservar el gobierno del Estado y para ese efecto introduce la democracia como forma de gobierno. Así, en una democracia la organización del poder del Estado es una decisión del pueblo, ya sea por el ejercicio del poder constituyente, ya mediante el ejercicio de los poderes constituidos que pueden organizar el Estado en las cuestiones que no son fundamentales. Pero también corresponde al pueblo lo concerniente a las actuaciones del Estado. Por tanto, la actividad del Estado está determinada y es ejercida por el pueblo.

\footnotetext{
Pitkin, Hanna, obr. cit. p. 242.

Schmitt, Carl, obr. cit. p. 221.

Véase, Böckenförde, Ernst, obr. cit. p. 52.
} 


\section{b) La democracia y el Estado}

El principio de democracia adhiere a la idea de que el pueblo ejerce el poder del Estado, de manera directa o indirecta. En este sentido, el enunciado de que el pueblo es el titular del poder del Estado excluye como titulares a todo otro posible titular, cualquier clase de hombres singulares, dioses o ideas ${ }^{56}$. Sin embargo, en la medida que la democracia moderna es una democracia representativa, en la mayoría de los casos la decisión del pueblo no será tomada por el pueblo mismo, sino por sus representantes. No obstante, la acción de los representantes, así como la de todos los órganos del Estado, debe poder entenderse o explicarse como proveniente, esto es, debe poder ser atribuida al pueblo.

La democracia no significa, dado que el gobierno del Estado le corresponde al pueblo y el destinatario del poder del Estado es también el pueblo, que la relación de dominación política entre el Estado y el pueblo se cancele, sino, más bien, como señala Böckenförde, "se organiza de tal forma que su ejercicio se constituye, se legitima y controla por el pueblo, en suma por los ciudadanos, y se presenta en esta forma como autodeterminación y autogobierno del pueblo, en los que todos los ciudadanos pueden participar en condiciones de igualdad" ${ }^{\prime 57}$.

La democracia como principio constitucional se dirige a regular el ejercicio del poder del Estado y no la vida de la sociedad estatal. En ese sentido, el principio de la democracia no exige que los grupos sociales se organicen de manera democrática, esa organización está a disposición de la decisión política del Estado, con todos los límites a las que dichas decisiones están expuestas, especialmente los límites que los derechos fundamentales establecen ${ }^{58}$.

\section{c) La democracia como principio constitucional}

El principio de la democracia como principio constitucional afirma dos cosas. En primer lugar, que la forma de gobierno del Estado es la de una democracia, sin embargo, también designa una concreta forma a la cual el ejercicio del poder político del Estado debe organizarse y ejercerse: "Su contenido es el de que el poder del Estado ha de articularse de tal forma que tanto su organización como su ejercicio deriven siempre de la voluntad del pueblo o puedan ser atribuidos a él" 59 .

El control que el pueblo ejerce sobre el poder del Estado es, entonces, el criterio sobre el cual se erige, desde esta perspectiva, la organización estatal democrática,

\footnotetext{
Böckenförde, Ernst, obr. cit. p. 54. Sobre el concepto de pueblo como centro de imputación de las formas de legitimación, véase Marshall, Pablo, obr. cit.

57 Böckenförde, Ernst, obr. cit. p. 53.

58 Böckenförde, Ernst, obr. cit. p. 53.

59 Böckenförde, Ernst, obr. cit. p. 47.
} 
que se presenta, entonces, "como autodeterminación y autogobierno del pueblo" en el que los ciudadanos del pueblo participan en condiciones de igualdad y libertad ${ }^{60}$.

\section{La decisión democrática como la decisión de la mayoría}

El principio de la decisión de la mayoría está plenamente justificado y está conectado de manera estrecha con la igualdad y la libertad política y que se deduce de ellas. En ese sentido, no se trata de un último recurso ante la imposibilidad del consenso $^{61}$.

Si se requiere para la toma de las decisiones en la democracia que todos los ciudadanos sean tomados como iguales en su libertad política, la democracia exige que sea la mayoría la que decida. En la democracia, la minoría no tiene el derecho de decidir, porque al hacerlo no se respetaría la igualdad política de los ciudadanos. Si se exige más que la mayoría, se está considerando que la decisión de la minoría tiene más valor. Si se exige menos que la mayoría, se está considerando que la decisión de la mayoría tiene menos valor.

En la base de este principio, además de las consideraciones de igualdad política, está la consideración pluralista de que todas las opiniones políticas cuentan por igual. Esta última, tiene una especial relevancia cuando se aplica tanto a las opiniones que requieren el cambio como a las que defienden el statu quo. Los quórum, reforzados no se presentan, bajo este punto de vista, como más democráticos, sino como una decisión constitucional a favor del statu quo ${ }^{62}$.

La justificación de las mayorías cualificadas, como limitación al principio democrático de la decisión de la mayoría, debe sostenerse desde el principio del Estado de derecho, como antidemocrático.

60 Böckenförde, Ernst, obr. cit. p. 53.

${ }^{61}$ Cft. Molina, Hernán, obr. cit. pp. 182-183.

62 Böckenförde, Ernst, obr. cit. pp. 92-93. La necesidad de una primacía del statu quo sobre la innovación, solo está justificada para cautelar la integridad del orden jurídico, mediante el establecimiento del principio de la decisión por mayoría por sobre del principio de equivalencia de las opciones: "En efecto, cuando se vota un proyecto de ley, esto es, acerca de la innovación del ordenamiento, el principio de equivalencia requeriría que tanto el proyecto como la oposición al mismo necesitasen la misma mayoría para triunfar, lo que supondría que ambos se sometiesen a votación y que para ambos se exigiese la mayoría de los votos emitidos. Sin embargo no ocurre así sino que, derrotado el proyecto por no haber obtenido la mitad más uno de los votos, sino por ejemplo, solo la mitad, no es preciso votar por la continuidad de la norma, que se produce por el simple hecho de no haber prosperado la opción reformadora" (De Otto, Ignacio, Derecho Constitucional. Sistema de Fuentes, Ed. Ariel, Barcelona,1988, p. 60). 
En este sentido, la idea de que la democracia debe basarse en un consenso constante sobre los asuntos políticos, es contradictoria con la idea que en la democracia las decisiones son tomadas por la mayoría. La igualdad de los ciudadanos que conforman la mayoría los provee de un derecho a poder decidir, por sobre la decisión del mantenimiento del statu quo de la minoría. Así, el principio del consenso que tiene una justificación allí donde presupone la participación y cooperación de todos los ciudadanos, no puede constituirse en un principio de decisión democrático ${ }^{63}$.

Los límites a decisión de la mayoría son puestos de manera externa por el principio del Estado de derecho, y se encuentran justificados allí cuando tienen como finalidad proteger a minorías sensibles de ser abusadas o para proteger al sistema democrático mismo. En este último sentido, queda vedado a la mayoría alterar las reglas exigidas por la libertad y la igualdad política, que exigen cierta configuración institucional: del derecho electoral, de la regulación de los partidos políticos y de la garantía de los derechos fundamentales de participación política. En palabras de Böckenförde, "no cabe de que la actual mayoría se imponga a sí misma como un todo, y de que, haciendo uso de las ventajas que la posesión legal del poder le atribuye, cierra tras de sí la puerta abierta a través de la que ella misma entró" ${ }^{64}$.

\section{La legitimación democrática}

\section{a) La legitimación como forma de imputación del ejercicio del poder del Estado al pueblo}

En la medida que el principio de la democracia exige que el poder del Estado derive del pueblo de modo concreto, el ejercicio de las competencias estatales exige que exista "una cadena ininterrumpida de legitimación democrática" que permite retrotraer la decisión del Estado al pueblo mismo. Ello no dice relación solamente con la instalación del órgano estatal que actúa, sino también con el ejercicio de la competencia por parte de dicho órgano ${ }^{65}$.

El ámbito de legitimación se extiende a toda la esfera de los asuntos estatales, no limitándose a aquellos asuntos donde el Estado actúa en relaciones de autoridad, sino a todas las actividades que el Estado ejerce de hecho. Por ejemplo, cuando el Estado actúa como un particular, comprando un bien en el comercio, su actividad debe ser objeto de legitimación democrática, de la misma manera que es causa de legitimación la dictación de una ley. El objeto concreto de legitimación es el ejercicio de toda la actividad del Estado.

63 Böckenförde, Ernst, obr. cit. p. 94.

64 Böckenförde, Ernst, obr. cit. p. 95.

65 Böckenförde, Ernst, obr. cit. p. 55. 


\section{b) Formas de legitimación democrática}

Para lograr la finalidad de la legitimación puede recurrirse a diversos modos o formas de legitimación. Dichas formas de legitimación pueden operar simultáneamente o por separado. Sin embargo, si bien pueden concurrir en diversa magnitud, no puede faltar totalmente ninguna de ellas, pues se dirigen a legitimar cuestiones distintas.

\section{(i) Legitimación democrática funcional e institucional}

Esta forma de legitimación apela a la organización institucional que el poder constituyente ha realizado mediante la configuración de los órganos del Estado. En el ejercicio de dicho poder, el pueblo le ha atribuido funciones a dichos órganos, lo que les confiere una autonomía respecto de los demás órganos en relación al ejercicio del poder del Estado.

Esta es una forma de legitimación abstracta, pues solo se refiere al órgano del Estado en cuestión y a su competencia in abstracto. Para la legitimación de la configuración personal del órgano y el ejercicio concreto de la competencia se requiere la concurrencia de otras formas de legitimación concreta, que aparecerán como complementarias $^{66}$.

La legitimación concreta es fundamental en la medida que impide la autonomización del ejercicio del poder respecto del pueblo. Así, el argumento de que la actuación de un órgano estatal está legitimada en la medida que dicho órgano está establecido constitucionalmente, no es suficiente desde el punto de vista democrático. Se requiere que la actuación de dicho órgano responda a una legitimación democrática concreta.

\section{(ii) Legitimación democrática orgánico-personal}

Esta forma de legitimación consiste en que en la generación concreta de los titulares de los órganos del Estado debe existir una cadena de legitimación que se retrotraiga hasta el pueblo. Ello implica que la designación de los titulares de dichos cargos debe ser hecha por el pueblo (inmediata) o por otros órganos elegidos por él (mediata). La diferencia entre la designación inmediata o la mediata será la mayor o menor dignidad democrática del órgano y la necesidad de concurrencia de otras formas de legitimación en mayor medida. Lo decisivo, señala Böckenforde, "es que la cadena de legitimación no se vea interrumpida por la intervención de un órgano o de un cargo no legitimado democráticamente o no legitimado así de forma suficiente ${ }^{\prime 67}$.

\footnotetext{
66 Böckenförde, Ernst, obr. cit. p.57.

${ }^{67}$ Böckenförde, Ernst, obr. cit. p.58. Entre las cuestiones que se plantean a propósito de está forma de
} 
Esta forma de legitimación apunta a legitimar el acceso del titular al órgano, pero no garantiza, de manera alguna, que una vez instalado, dicho titular ejerza las competencias con que cuenta de espaldas a la voluntad del pueblo que, directa o indirectamente, lo colocó en ese lugar. Para ese caso se requiere de una legitimidad material.

\section{(iii) Legitimación democrática material o de contenido}

Esta forma de legitimación consiste en asegurarse de que, en lo que se refiere al contenido de los actos del Estado, el ejercicio del poder del Estado pueda entenderse como una decisión del pueblo o, por lo menos, se concilie con la voluntad del pueblo. Esta forma de legitimación es, nuevamente, una garantía para que los titulares de los órganos del Estado, una vez instalados y satisfecha la legitimación orgánico-personal, no puedan actuar con autonomía respecto de la voluntad del pueblo.

Esta legitimación se produce por dos vías: (i) mediante el mandato de vinculación a la ley, que asume la dignidad de la expresión del pueblo, en la medida que emana del órgano de mayor representatividad democrática que es el parlamento; y (ii) mediante la responsabilidad de las autoridades, ejercida a través del control correspondiente y "adecuado para el tipo de tareas asumidas". Esta responsabilidad se hace valer directamente por el pueblo por medio de las elecciones periódicas, para aqueIlas autoridades que cuenten con legitimación personal inmediata y de esa manera se confunden formalmente con la legitimación orgánico-personal. Para las autoridades sin legitimación personal inmediata las responsabilidades se ejercerán mediante los derechos de control y destitución que tienen los representantes del pueblo ${ }^{68}$.

Estas dos vías de legitimación material se correlacionan y equilibran. Allí donde los mecanismos de responsabilidad son muy tenues o inexistentes se requerirá una vinculación a la ley estricta. Ese es típicamente el caso de la función jurisdiccional, en el cual es patente la ausencia de control y las posibilidades de destitución son marginales. Por otro lado, en el caso del ejercicio de las atribuciones que no tienen la posibilidad de una vinculación a la ley, la legitimidad material se realizará mediante posibilidad de dirigir sus acciones mediante instrucciones de órganos legitimados y de hacer valer, en su caso, responsabilidades ${ }^{69}$. Este es el caso en el que se encuen-

legitimación surge la de si todos los que participan de las decisiones de un órgano colegiado deben estar legitimados o solo se requiere la legitimación del órgano como tal, siendo posible la legitimación con la participación de una mayoría legitimada orgánico-personalmente. Una solución equilibrada a este problema parece ser la permisión de integrantes no legitimados si se deja en manos de la mayoría legitimada la posibilidad de tomar una decisión positiva (Böckenförde, Ernst, obr. cit. pp. 59-61).

68 Böckenförde, Ernst, obr. cit. pp. 62-63. Este análisis debe diferenciar entre los sistemas en los que el Jefe del gobierno recibe su legitimación directamente del pueblo y los sistemas en los cuales su legitimidad es mediada por el parlamento.

69 Böckenförde, Ernst, obr. cit. p.63. 
tra, típicamente, la administración del Estado en el ejercicio de su función política o su función legislativa; bajo la supervigilancia jerárquica, dirigiendo su acción por instrucciones y sujeto a la responsabilidad política en el caso de los funcionarios de confianza.

(iv) Balance entre formas de legitimación concreta

La ausencia de legitimación material solo está justificada en casos excepcionales. Tal es el caso de las autonomías constitucionalmente garantizadas y las razones de carácter ineludible basadas en el tipo de actividad. Con todo, en estos casos deberá garantizarse plenamente su legitimidad orgánico-personal y someter al ámbito de acción de la competencia del órgano a una estricta delimitación. Al contrario, en los casos en que hay una garantía estricta y plena de legitimidad material, podrá flexibilizarse las exigencias de legitimidad orgánico-personal ${ }^{70}$.

\section{La democracia en la Constitución Política de Chile}

\section{a) La democracia como principio de organización del Estado}

El artículo $4^{\circ}$ de la Constitución Política establece que "Chile es una república democrática". La interpretación del rol de dicho artículo no es una cuestión relevante en la doctrina nacional, que no escatima en expresar su importancia, pero no le confiere mayor eficacia normativa. Así, la disposición que establece la democracia puede ser entendida en dos sentidos erróneos. El primero, como una disposición que consagra un principio descriptivo. En este sentido, tal disposición constituye una abstracción de la concreta organización de democracia representativa que está regulada en los artículos siguientes de la Constitución (por ejemplo, los que regulan la elección del Presidente de la República y de los integrantes del Congreso Nacional). El segundo, como un principio programático. La democracia en cuanto principio de gran abstracción y falta de determinación se constituye en un ideal a ser conseguido. Especialmente relevante ha sido esta segunda lectura en el discurso para eliminar los "enclaves autoritarios" de la dictadura militar ${ }^{71}$.

La forma correcta de interpretar la disposición del artículo $4^{\circ}$, sin embargo, es confiriéndole una eficacia normativa mayor. En ese sentido, la democracia exige, por un lado, como se ha visto más arriba, el respeto de la igualdad y la libertad política y de las formas de toma de decisiones que dichos principios suponen y, por otro, de la exigencia de la legitimidad democrática de toda la organización y la actividad estatal.

70 Böckenförde, Ernst, obr. cit. pp. 64-66.

71 Kazor, Camel, Constitución, principio democrático y reformas constitucionales /en/ Revista de Derecho de la Universidad Austral de Chile, № 13, 2002. 


\section{b) Las formas de legitimación en la Constitución Política}

Todos los órganos establecidos en la Constitución Política cuentan con una legitimidad democrática funcional en la medida que esta está legitimada por medio del ejercicio del poder constituyente del pueblo. La falta de legitimidad funcional puede presentarse en la medida que se cuestiona la participación del pueblo en la adopción de la Constitución. Sin embargo, de esa forma lo que se discute es la falta de legitimidad de la Constitución y no simplemente la falta de legitimidad democrática funcional de los órganos por ella establecidos. La pregunta por la falta de legitimidad de la Constitución es una cuestión que no puede ser tocada aquí, sin embargo, puede decirse que la cuestión de la falta de legitimidad popular de origen, no cancela la posibilidad de la imputación del poder constituyente al pueblo, en la medida que uno entiende que dicha imputación siempre es conflictiva desde el punto de vista de un orden establecido. El análisis de las otras formas de legitimación democrática presta utilidad para determinar cómo el principio de la democracia puede influir u orientar la labor de los órganos del Estado.

\section{(i) El Presidente de la República y el Gobierno}

El Presidente se legitima, en primer lugar, mediante su elección por el voto popular. Al tener una gran legitimación orgánico-personal directa, el Presidente requiere una menor dosis de legitimación material. En ese sentido, el Presidente si bien está sometido a la fiscalización del Congreso, no es responsable políticamente ante él y este no puede hacerlo responsable por actos de su gestión por encontrarse de espalda a los intereses del pueblo. No obstante ello, tanto el Presidente de la República como (y especialmente) sus colaboradores están sometidos a la Constitución y a la ley.

El Presidente de la República contribuye, como órgano legitimado de manera directa, a la legitimación orgánico-personal mediata de numerosas autoridades estatales y no solo aquellas que se encuentran subordinadas a él, como los ministros, intendentes y gobernadores. Así, participa en el nombramiento de los miembros del Poder Judicial (art. $78 \mathrm{CPol}$ ), del Fiscal Nacional (art. $85 \mathrm{CPol}$ ), algunos ministros del Tribunal Constitucional (art. $92 \mathrm{CPol}$ ), del Contralor General de la República (art. 98 CPol) y de los consejeros del Banco Central.

\section{(ii) El Congreso Nacional}

El parlamento está legitimado de manera muy fuerte por medio la elección de sus integrantes de una manera directa por parte del pueblo. El Congreso es, además, el principal instrumento del pueblo para la atribución de la legitimidad material. En la medida que el parlamento es el órgano primario de la legislación, mediante su producción normativa se implementan las restricciones a las que quedan sujetos el resto de los órganos del Estado. Sin embargo, el Congreso también tiene un importante rol 
en la atribución de legitimidad orgánico personal, en la medida que está encargado de la ratificación de numerosas autoridades estatales (art. 53 inc. $1^{\circ} \mathrm{n}^{\circ} 5 \mathrm{CPol}$ ).

\section{(iii) El Poder Judicial}

Los tribunales tienen su legitimidad orgánico-personal limitada en la medida que son funcionarios de carrera y la reciben solo indirectamente, mediante la designación de sus integrantes por el Presidente la República. Ello con la limitación que implica que el Presidente realiza el nombramiento entre los miembros de una lista que le presenta la propia judicatura.

La legitimidad material en el caso de los jueces es especial. En la medida que no están sujetos a control por parte de los órganos representativos (art. $76 \mathrm{CPol}$ ), los tribunales requieren una sujeción a la ley de una manera más estricta que aquellos funcionarios cuyas actuaciones pueden ser corregidas o controladas por los representantes del pueblo. Si bien la sujeción estricta a la ley no está establecida expresamente para los jueces, como por ejemplo en la Constitución Española (art. 117.1) o la Ley Fundamental de Bonn (art. 97.1), ella puede deducirse del principio de la democracia establecido en el artículo $4^{\circ}$ de la Constitución Política ${ }^{72}$. No parece distinta la situación del Tribunal Constitucional. Sin embargo, ello exige consideraciones adicionales que no es posible desarrollar aquí.

\section{Bibliografía}

Barros, Enrique, La democracia como forma del poder: un enfoque normativo /en/ Estudios Públicos, Nº 26, 1987.

Bobbio, Norberto, La teoría de las formas de gobierno en la historia del pensamiento político: año académico 1975-1976, Fondo de Cultura Económica, México, 2001.

BÖCKENFÖRDE, ERNST, WOLFGANG, La democracia como principio constitucional, Ed. Trotta, Madrid, 2002.

VV. AA., La Democracia como Principio Constitucional, Ed. Trotta, Madrid, 2002.

Correa, Rodrigo, El Gobierno Judicial Ante La Constitución /en/ Gobierno Judicial, Instituto de Estudios Judiciales, Santiago, 2005.

De Otto, Ignacio, Derecho Constitucional. Sistema De Fuentes, Ed. Ariel, Barcelona, 1988.

72 Correa, Rodrigo, El gobierno judicial ante la constitución /en/ Gobierno Judicial, Instituto de Estudios Judiciales, Santiago, 2005; Schmitt, Carl, obr. cit. pp. 265-267.

Revista Chilena de Derecho y Ciencia Política - Vol. 3, № 1, Año 2, 2011 
Kazor, Camel, Constitución, principio democrático y reformas constitucionales /en/ Revista de Derecho de la Universidad Austral de Chile, NN 13, 2002.

Lastarria, José Victorino, Elementos de Derecho Público, 1865.

Marshall, Pablo, La soberanía popular como fundamento del orden estatal y como principio constitucional /en/ Revista de Derecho de la Universidad Católica de Valparaíso, № 35, 2010.

Molina, Hernán, Instituciones Políticas, LexisNexis, Santiago, 2006.

Ovejero lucas, Félix; Martí Màrmol, José Luis; Gargarella, Roberto, Nuevas ideas republicanas: autogobierno y libertad, Paidós Ibérica, Barcelona [etc.], 2004.

Pettit, Philip, Republicanismo, una teoría sobre la libertad y el gobierno, Paidós, Barcelona, 1999.

Pitkin, Hanna Fenichel, El concepto de representación, Centro de Estudios Constitucionales, Madrid, 1985.

Roldán, Alcibíades, Elementos de Derecho Constitucional de Chile, Imprenta Lagunas \& Co., Santiago, 1924.

SChmitt, CARL, Teoría de la Constitución, Alianza, Madrid, 1983.

Silva, Alejandro, Tratado de Derecho Constitucional, Ed. Jurídica de Chile, Santiago, 1963.

Vivanco, Ángela, Curso de Derecho Constitucional, Ed. Universidad Católica de Chile, Santiago, 2004. 